\title{
st \\ As mônadas físicas como unidades gerativas no Sistema da natureza de Maupertuis
}

\author{
Maurício de Garvalho Ramos
}

\section{INTRODUÇÃO}

A presente tradução do Systême de la nature (Sistema da natureza) finaliza nosso projeto de tradução das obras biológicas de Maupertuis da qual fizeram parte a Lettre XIV. Sur la génération des animaux (Carta XIV. Sobre a geração dos animais) (Maupertuis, 2004) e a Vénus physique (Vênus física) (Maupertuis, 2005). Na presente introdução, apresentaremos o último passo teórico dado por Maupertuis em sua passagem pelas ciências do orgânico, o qual envolve um importante movimento em direção à física das qualidades dado por um newtoniano e físico-matemático da metade do século xvirI. Juntamente com as introduções que acompanharam as outras traduções (cf. Ramos, 2004; 2005) pretendemos ter concluído uma análise preliminar do desenvolvimento de um importante esforço de compreensão dos fenômenos da geração orgânica que envolveu os principais sistemas de filosofia natural da época das Luzes.

A primeira edição do Sistema da natureza foi publicada em latim, em Erlagen, sob o pseudônimo de Dr. Baumann, tendo por título Dissertatio inauguralis metaphysica de universalis naturae systemate pro gradu doctoris habita (Dissertação metafísica inaugural sobre o sistema da natureza universal para a obtenção do grau de doutor). Na Advertência que introduz o Sistema da natureza, Maupertuis informa que a primeira edição latina é de 1751. Entretanto, Mary Terrall afirma que não há evidência que corrobore esse fato, parecendo mais provável que a obra não tenha sido impressa antes de $175^{2}$ (cf. Terrall, 2002, p. 322). A autora faz um detalhado estudo para sustentar sua interpretação, apresentando valiosas informações sobre as circunstâncias históricas em que se situa a obra (cf. Terrall, 2002, p. 322-7). Estão entre as outras edições que apareceram após a edição latina uma tradução francesa, sem local e ano de publicação, uma versão com o título Essai sur la formation des corps organisés (Ensaio sobre a formação dos corpos organizados), de 1754 (Berlim-Paris), posteriormente reimpressa em Lyon como Sistema da natureza no conjunto das Oeuvres (Obras) de Maupertuis em quatro volumes (1756 e 
1768). A presente tradução foi feita a partir do volume dois de uma reimpressão em fac-símile desta última coletânea (Maupertuis, 1965 [1768]).

\section{A geraÇão orgÂNIGA PELA AÇÃo DAS AFINIDADES QUímiCAS}

Na Vênus física, obra de 1745 na qual Maupertuis apresenta sua primeira teoria da geração, a suposição principal que sustenta a explicação dos fenômenos gerativos é a ação de atrações newtonianas na forma de afinidades químicas eletivas, propostas pelo químico francês Etienne-François Geoffroy, que agregam as partes orgânicas diferencialmente conforme sua posição na estrutura do embrião. Além do poder explicativo que a teoria adquire com tal suposição, Maupertuis reforça a adequação da teoria a partir da analogia entre a formação das árvores químicas (organismos minerais) e a geração das árvores vivas (organismos vegetais) (cf. Ramos, 2005, p. 89-93).

A explicação analógica de Maupertuis pela comparação da formação de cristalizações arborescentes com a geração de plantas vivas depende de uma redução epistemológica que, por sua vez, funda-se em uma conjectura ontológica. Se supusermos que os fenômenos complexos de formação dos organismos resultam da ação das mesmas forças que atuam no mundo mineral, os recursos oferecidos pela ciência dinâmica serão suficientes para explicar uma parte dos fenômenos vitais que ainda permanece envolta em certo mistério. De fato, as teorias da geração dominantes na época de Maupertuis negavam que seria possível explicar a geração do embrião apenas com a física, sem importar que esta última tivesse uma orientação mecanicista, dinamista ou vitalista. As noções combinadas de preexistência e embutimento dos germes colocavam o fenômeno da geração orgânica ontologicamente fora do domínio físico e, portanto, da física. Afirmando o caráter necessariamente milagroso da geração, pretendia-se salvar o esquema mecanicista através de uma importante restrição do âmbito de fenômenos passíveis de explicação pela física. Na Vênus física (cap. XII e xIII), Maupertuis mostra detalhadamente que, além do ônus filosófico presente na utilização da metafísica para explicar fenômenos ordinários da física, as consequências físicas daí decorrentes levam a inadequações empíricas inaceitáveis (cf. Ramos, 2005, p. 86-7). Guardadas as devidas proporções, problemas éticos da ciência contemporânea ainda fazem com que o milagre ronde os estágios iniciais da embriogênese, o que mostra a disposição das metafísicas genéticas atuais (agora sem o embutimento e sem a preexistência anterior à fecundação) de pagar o ônus filosófico que acompanha a ideia de préformação dos germes. Voltando ao século xvıII, a conjectura genética que a Vênus física oferece inscreve-se na oposição entre epigênese e pré-formação, com suas raízes profundas no problema filosófico tradicional do devir. A tese da formação (e do posterior 
As mônAdAS físigas como unidAdes gerativas no Sistema da natureza...

crescimento) de organismos pela agregação ou justaposição de partes opõe-se à tese da formação por intussuscepção, um mecanicismo de geração pelo crescimento de dentro para fora a partir de uma estrutura orgânica pré-formada. Podemos localizar o reflexo desta oposição em questões bem particulares da ciência da época. Conforme apontamos em nota à nossa tradução da Vênus física (cf. Maupertuis, 2005, p. 162, nota 4.3), o químico Guillaume Homberg critica a tentativa de estabelecer analogias entre as árvores químicas e as orgânicas. Para ele, os ramos das árvores químicas

assemelham-se bastante a uma verdadeira vegetação quando observamos apenas a figura externa; mas quando consideramos que uma verdadeira planta é um corpo orgânico cujas partes servem para extrair o sumo da terra, para preparar esse sumo para a nutrição e o crescimento da planta e para produzir, enfim, sementes que também são pequenos corpos orgânicos, que se desenvolvem em novas plantas através da nutrição que absorvem; e quando, ao contrário, vemos em nossas vegetações artificiais que elas são apenas simples cristalizações ou reuniões de alguns pequenos pedaços de metal, que o acaso colocou uns sobre os outros sem ordem e sem qualquer parte orgânica, a comparação que quisermos fazer entre elas e a verdadeira vegetação das plantas não poderá de forma alguma subsistir (Homberg, 1710, p. 428).

Mesmo que plantas químicas e biológicas exibam morfologias semelhantes, a analogia também deve, para ser aceitável, estender-se à fisiologia, o que evidentemente não acontece. $\mathrm{O}$ autor também recorre a um princípio biogenético de continuidade do orgânico, a saber, plantas verdadeiras são organismos que produzem sementes que também são corpos orgânicos. Essa posição é, em alguma medida, de caráter pré-formacionista, pois entende que a semente já deve possuir uma estrutura organizada. Em suma, o caráter morfofisiológico dos organismos não poderia ser reproduzido a partir da diversidade de interações permitidas pela ação das atrações eletivas. A morfofisiologia que opera no nível dinâmico-corpuscular não restituiria a morfofisiologia do nível biológico.

Esse problema parece-nos ser um dos principais a ter motivado Maupertuis na construção da segunda versão da teoria da geração desenvolvida no Sistema da nature$z a$. Já na conclusão da Vênus física, o autor apresenta um conjunto de conjecturas que revelam tanto uma crítica a sua primeira teoria como o teor de seu futuro desenvolvimento. $\mathrm{O}$ autor chama a atenção para o caráter hipotético de sua teoria, afirmando não estar completamente satisfeito com seu “esboço de sistema” (Maupertuis, 2005, p. 147). Expõe o projeto de ampliar sua hipótese com a ideia de que as partes seminais são dotadas de uma forma rudimentar de instinto: 
Esse instinto dos animais, que os faz buscar o que lhes convém e fugir do que lhes é prejudicial, não pertence às menores partes de que um animal é formado? Esse instinto, apesar de disperso nas partes das sementes e menos forte em cada uma do que no animal todo, não bastaria, entretanto, para produzir as uniões necessárias entre essas partes, pois vemos que, nos animais completamente formados, ele faz seus membros se moverem? (Maupertuis, 2005, p. 147).

O instinto exibe uma combinação de propriedades que parece perfeita para corrigir a potencial insuficiência da tese das atrações eletivas. No movimento voluntário do animal adulto, o instinto atua tanto dinamicamente, como causa física do movimento, quanto teleologicamente, como causa orgânica e fisiológica que conduz o movimento na direção do que é biologicamente melhor. Na geração do organismo, o caráter voluntário do movimento vital continuaria a existir, atribuindo às partes seminais a finalidade biológica necessária à formação da diversidade de estruturas e de interações exibidas pelo organismo. AVênus física certamente é, como dissemos, "uma conjectura para explicar a geração dos animais que rejeita a insuficiência dos 'sistemas modernos' [preexistência e embutimento] sem abandonar os princípios científicos que a época das Luzes herdou da nova física do século xvII" (Ramos, 2005, p. 79). O Sistema da natureza, por sua vez, representa o enfrentamento de sérias dificuldades decorrentes da fidelidade a esses princípios científicos. Trata-se da exploração de uma conjectura psicofísica alternativa para o estudo dos fenômenos genéticos que se desvia do projeto da dinâmica físico-matemática que floresce no Iluminismo. Mas tal desvio não retrocede para o animismo que, em linhas gerais, caracterizou a ciência pré-moderna.

\section{UMA FÍSICA DO DESEJO, DA AVERSÃO E DA MEMÓRIA}

O Sistema na natureza inicia com uma descrição das sucessivas generalizações ocorridas na física para explicar os fenômenos naturais. Primeiramente a matéria extensa e o movimento foram considerados suficientes para explicar toda a natureza. Posteriormente são incluídas a impenetrabilidade, a mobilidade e a inércia. Por fim, Newton propõe a atração. Como vimos, na Vênus física, a dinâmica newtoniana que resultou desse desenvolvimento era suficiente, como ciência de base, para explicar o campo fenomênico do orgânico. Bastaria adicionar a suposição de atrações que sigam outras leis, para explicar a formação dos corpos químicos que seriam, por sua vez, uma forma mais simples de formação dos corpos dos seres vivos. Mas, no Sistema da natureza, Maupertuis toma outro rumo: 
As mônAdAS físigas como unidAdes gerativas no Sistema da natureza...

Mas, mesmo com essas atrações, a menos que se suponha, por assim dizer, que haja tantas delas quantas partes diferentes existem no interior da matéria, ainda estamos bem longe de explicar a formação de uma planta ou de um animal (cap. IV).

O problema que acima apontamos aparece de forma explícita. Para tratar dos fenômenos gerativos, a física da atração deveria criar tal multiplicidade de forças, regulada por leis igualmente tão distintas, que inviabilizaria a utilização da metodologia moderna de buscar por teorias ou sistemas teóricos universais na explicação dos fenômenos. De certa forma, postular forças especiais para explicar fenômenos particulares está metodologicamente mais próximo de uma física qualitativista das formas substanciais e das qualidades ocultas que, no estudo dos fenômenos biológicos, traduz-se em uma espécie de fisiologia das almas.

Mais uma vez, o modelo atomista da geração por agregação ou composição de partes não resiste diante da crítica de sua insuficiência para explicar o caráter teleológico da geração orgânica. É necessário postular um novo princípio organizador, o que Maupertuis faz propondo uma nova analogia:

Se se quer dizer sobre isso [a geração dos organismos] alguma coisa que compreendamos, ainda que seja compreendida apenas com base em alguma analogia, é preciso apelar para algum princípio de inteligência, para alguma coisa semelhante ao que em nós chamamos desejo, aversão, memória (cap. xvi).

Esse princípio de inteligência será a nova fundamentação de todas as explicações sobre a geração dos corpos organizados na teoria de Maupertuis. Uma inteligência seminal ora aproxima ora afasta as partes orgânicas de modo a estabelecer as necessárias preferências que essas partes deverão exibir ao combinarem-se para a adequada estruturação do embrião. Uma vez produzida a estrutura, a inteligência atuará como memória genética que perpetua a forma própria da espécie ao longo das gerações. A posição correta que cada parte ocupa no todo orgânico pode ser retomada graças à lembrança que a partícula guarda da posição que ocupava no organismo. Com tais ideias, Maupertuis elaborou um sistema natural sobre a geração que poderia superar os problemas dos sistemas anteriores, fundamentalmente o sistema dos antigos, de Harvey, de Descartes e o da preexistência-embutimento dos germes, lembrando que dos dois primeiros Maupertuis aproveita muitos elementos para sua teoria. Seu sistema explicaria não apenas a reprodução ordinária (sexuada) como os modos assexuados ainda embaraçosos na Vênus física, a saber, a regeneração e a partenogênese - a primeira dispensa a mistura dos líquidos seminais e a segunda reforça a versão ovista da preexistência. 
Outro conjunto de novas conjecturas presentes no Sistema da natureza é bastante arrojado. Nessas novas conjecturas, a explicação genética estende-se até a primeira origem dos corpos organizados, sendo também aplicada para explicar a geração de corpos não-vivos, como os minerais e os metais. Em uma ousada associação entre a história da Terra e a da vida, Maupertuis envolveu-se com um problema que terá um longo destino, a saber, o da relação entre a origem da vida e a geração espontânea. A esse respeito o autor diz que

tudo nos faz crer que todas as matérias que vemos sobre a superfície de nossa Terra foram fluidas [...] nesse estado de fluidez [as matérias] se encontravam na mesma situação que esses líquidos nos quais nadam os elementos que devem produzir os animais (cap. XLIX).

Desde a Vênus física, a base material da geração ordinária é a mistura de partes seminais oriundas dos dois parentes que forma, assim, o fluido seminal. Na medida em que novos tipos de geração são considerados, essa condição fluida vai sendo modificada pela elaboração teórica: na partenogênese, basta o fluido contido em um organismo; na geração espontânea, o fluido encontra-se fora de organismos ancestrais. Por fim, como o vimos declarar na citação, esse mesmo fluido estaria presente nas condições primordiais da Terra, nas quais teria ocorrido a formação dos possíveis primeiros corpos organizados. Em suma, partículas gerativas em estado de fluidez e dotadas de inteligência formam a estrutura seminal universal, pois, nesse estado de fluidez primitiva, "os metais, os minerais, as pedras preciosas foram bem mais fáceis de formar-se que o inseto menos organizado. As partes menos ativas da matéria teriam formado os metais e os mármores, as mais ativas, os animais e o homem" (cap. XLIX).

\section{A transformação das ESPÉGIES}

No capítulo xxxı do Sistema da natureza, Maupertuis afirma a superioridade de seu sistema graças a sua capacidade de explicar certos fenômenos de hereditariedade juntamente com a explicação da própria formação do feto: tais como a semelhança com os pais, a geração dos monstros e a hibridização. Nos capítulos seguintes, o autor explica a fixidez e a mudança presentes nesses fenômenos, recorrendo à possibilidade das qualidades psíquicas das partes seminais formarem hábitos mais ou menos tenazes que, por sua vez, produzem estruturas mais ou menos estáveis ao longo das gerações. Com isso, Maupertuis considera os acidentes e a mestiçagem como fenômenos que podem contribuir para o enriquecimento da diversidade. Contrariamente à interpre- 
As mônAdAS físigas como unidAdes gerativas no Sistema da natureza...

tação corrente, ele não considera tais fenômenos como desvios da natureza. Bem ao contrário, apresenta uma conjectura no capítulo XIV que se tornou célebre nos estudos sobre a história do evolucionismo: pelo processo de fixação de acidentes ocorridos nas partes seminais, as mais diferentes espécies poderiam surgir de apenas dois indivíduos. "Cada grau de erro teria produzido uma nova espécie" e a atual diversidade infinita de animais talvez cresça com o tempo.

Não é o caso de ponderarmos aqui as posições acerca do significado que tais afirmações possuem para a história da biologia, o que incluiria uma análise crítica da associação do transformismo às ideias de Maupertuis. O que nos parece claro é que a obra biológica de Maupertuis representa um importante passo no processo de temporalização da história natural e mesmo das ciências naturais em geral. Roger faz um importante estudo a esse respeito tomando as ideias de Buffon como objeto: "Todo mundo está de acordo em datar no final do século xviı a introdução da história e a considerar Buffon como um dos principais autores dessa transformação das ciências naturais" (Roger, 1992, p. 193). Pensamos que o mesmo pode ser dito, em grau ainda maior, com relação a Maupertuis. O que torna difícil a análise desse passo é a avaliação da medida em que o processo de temporalização relaciona-se com a formulação de princípios universais ou leis de evolução orgânica - e sobre o caráter de tais princípios e leis. Contudo, mesmo na ausência de tais leis, há em Maupertuis um novo sentido de erro e de desvio natural que revela o caráter histórico de sua teoria da geração. Além disso, podemos entender que há dois níveis de historicidade da história natural, a saber, um primeiro que incorpora os prodígios e as maravilhas como parte dos processos naturais, explicando-os em termos de desvios a serem corrigidos pelas leis naturais imutáveis, e um segundo que interpreta tais prodígios não como desvios, mas como efetivas novidades a serem incorporadas como tais à ordem natural. $\mathrm{O}$ primeiro nível já estava bem estabelecido na época de Maupertuis, mas é em sua obra, e na de Buffon, que o segundo nível aparece com clareza.

Voltando ao que diz Maupertuis, o processo de produção de novas espécies a partir dos dois indivíduos primordiais ocorre, ao que tudo indica, através de "geração ordinária" - reprodução sexuada, diríamos hoje. Contudo, vimos que o mecanismo mais primordial da geração é a geração espontânea e, assim, podemos discutir a ligação existente entre essas duas conjecturas sobre as origens, uma sobre a origem dos primeiros organismos ou da vida e a outra sobre a origem das espécies. Tal ligação será um dos elementos centrais das controvérsias futuras da biologia sobre as bases materiais da vida e da evolução, sobre a oposição entre abiogênese e biogênese e, para problemas mais específicos, sobre a origem evolutiva da reprodução sexuada. Como Maupertuis explicou em sua conjectura, quando as partes seminais ganham a condição de fluidez que caracteriza a produção do sêmen, elas se encontram na mesma situação primor- 
dial na qual estavam os primeiros elementos que deram origem aos primeiros corpos organizados. A mesma condição é encontrada em todas as gerações espontâneas ocorridas desde as origens. Isso significa que, tanto na geração ordinária ou sexuada como naquelas onde não há ancestrais organizados, o material genético está sujeito às mesmas contingências. Não há uma estrutura material (como nas atuais moléculas informacionais replicantes) que se mantém fixa ao longo de todo ciclo vital. Com isso, a conjectura de uma filogênese a partir de um casal primordial dificilmente guardaria correspondência com a regularidade evolutiva da diversidade biológica empiricamente observável.

Todas essas questões devem ser consideradas e melhor desenvolvidas, se quisermos avaliar a posição da teoria da geração de Maupertuis na história do pensamento evolucionista. Porém, elas não são, a nosso ver, suficientes para concluir que a teoria da geração de Maupertuis não tem nada a ver com a noção de transformação das espécies e que o Sistema da natureza não é um documento importante para a história da noção de evolução. Uma apreciação mais aprofundada da questão, que não é o caso de fazer nesta introdução, deve colocar em perspectiva a noção de evolução orgânica como ideia que se instala e se desenvolve na temporalização da história natural ocorrida no Iluminismo, uma perspectiva bem mais ampla e rica do que o estudo da origem do darwinismo ou dos "precursores" de Darwin.

\section{As MÔNADAS FÍSICAS GOMO UNIDADES GERATIVAS}

As partes seminais dotadas de atributos psíquicos postuladas por Maupertuis podem ser caracterizadas como participando de um modelo monadológico geral. O caráter psicofísico das partes é responsável pela produção e manutenção dinâmica do organismo e por sua natureza teleológica, garantida pela capacidade das partes perceberem sua posição no todo orgânico. Na parte, há uma representação do todo que coordena o movimento de geração de modo a reproduzir e conservar a estrutura ancestral. A utilização desse modelo, no estudo dos fenômenos vitais, foi comum no século xviı, podendo ser caracterizada mais especificamente como uma forma de monadologia física.

Ao comentar o conteúdo geral do Sistema da natureza, Duchesneau diz que nele há "uma conjectura epigenética fundada sobre uma espécie de monadologia física" (1982, p. 236). O autor discute, entre outras coisas, o distanciamento que essa forma de monadologia tem com relação a sua fonte leibniziana original. Em Leibniz, nunca haveria, como em Maupertuis, "aglomeração de partes nem dissolução de compostos orgânicos na natureza, mas apenas mudanças de estado de mônadas perceptivas" (Duchesneau, 1982, p. 238). Essa perspectiva é bastante frutífera para compreender o 
As mônAdAS físigas como unidAdes gerativas no Sistema da natureza...

sentido que o Sistema da natureza possui no quadro do desenvolvimento das ciências da vida modernas. Ao atribuir a inteligência diretamente à matéria, Maupertuis não torna a primeira um fundamento da segunda, como acontece na relação expressiva que a mônada leibniziana possui com o corpo, bem como com todo universo. Ao contrário das mônadas de Leibniz (1996, p. 244), as mônadas físicas de Maupertuis, por agirem na estruturação espaço-temporal do organismo, possuem janelas que permitem perceber sua vizinhança.

A natureza e a amplitude da percepção das mônadas físicas de Maupertuis conduzem a outro problema, teórica e historicamente essenciais, a saber, o problema dos níveis de organização biológica associado ao da natureza da unidade reprodutiva dos seres vivos. Na Carta XIV. Sobre a geração dos animais, Maupertuis discute "o quão 'orgânica' deve ser a parte mínima corporal capaz de reter o poder de gerar um novo organismo" (Ramos, 2004, p. 115). As observações de Needham e de Buffon, citadas no capítulo XLVII do Sistema da natureza, revelaram a Maupertuis que a existência de níveis de organização nos seres vivos torna muito mais difícil determinar qual seria a unidade gerativa; sobretudo, quando não há a diferença entre somático e genético, entre geração e constituição dos organismos. Tais problemas levaram Maupertuis a fazer, no final da Carta XIV, perguntas que, com as devidas reformulações decorrentes da instalação de novas imagens de ciência, continuariam a ser feitas até hoje:

Se esses corpos animados são as partes que devem formar o corpo de algum futuro animal, diríamos que partes animadas, cada qual com uma vida própria, chegam a se unir para formar apenas um corpo animado com uma única vida? Avida, divisível como a matéria, poderia ser reunida como ela? Mas como se faria essa união? Forças e atrações, tais como as que movem os grandes corpos do universo, os planetas e os cometas, mesmo aquelas que agem nas admiráveis produções que a química nos mostra, serão elas suficientes ou não seria preciso ainda alguma coisa a mais? (Maupertuis, 2004, p. 134).

Considerando, agora, conjuntamente os problemas da natureza e da amplitude da percepção dos elementos seminais e dos níveis de organização, chegamos ao que consideramos como a possível questão teórica mais importante ligada ao uso que Maupertuis faz dessa monadologia física. Uma mônada física típica seria uma espécie de átomo orgânico que possuiria internamente uma estrutura que guardaria uma relação com a estrutura completa do organismo. A natureza dessa relação pode ser de vários tipos. Tomando dois exemplos extremos, no germe preexistente há uma relação de identidade entre a estrutura do germe e a do adulto, originada por uma fonte externa milagrosa. Já na noção atual de genoma como uma agência diretora central, o germe esta- 
belece com o organismo uma relação de expressão funcional com uma dualidade estrutural - a parte passiva e organizada e a parte ativa organizadora, o genoma. (cf. Freitas, 2003, p. 142-51). Em tal caso a fonte de organização também é, como na preexistência, externa (cf. Freitas, 2003, p. 150). Em Maupertuis, a parte seminal pode perceber e representar apenas sua vizinhança, ou seja, há um “conhecimento” germinal local e parcial da estrutura do organismo completo. Isso nos parece suficiente para relativizar o caráter epigenético da teoria da geração de Maupertuis. Poderíamos provisoriamente dizer que ela é uma quasi-epigênese: a ação do agente gerativo psicofísico atua produzindo estruturas em vários níveis de organização, não como em uma epigênese típica cujo substrato ontogenético inicial é constituído por uma matéria homogênea contínua ou por um conjunto mais ou menos caótico de partículas, mas como uma epigênese parcial que se inicia a partir de mônadas físicas atípicas como unidades gerativas parcialmente pré-formadas. Em suma, a unidade gerativa e a unidade orgânica fundamental não estão determinadas por uma forma substancial (aristotelismo), por leis mecânicas (cartesianismo), nem por uma força vital (vitalismo), nem por um germe preexistente (preexistência e embutimento). Isso significa, a nosso ver, que embora Ibrahim esteja correta ao afirmar que Maupetuis não pode resolver a questão da determinação da unidade orgânica no sentido de uma monadologia física (cf. Ibrahim, 1992, p. 99), tal impossibilidade é fruto da temporalidade que Maupertuis associa a sua teoria da geração: as unidades gerativas e orgânicas não estão dadas de uma vez, mas constroem-se ao longo do tempo.

\section{O desafio de Diderot}

Nos capítulos x e XuI de seus Pensées sur l'interprétation de la nature (Pensamentos sobre a interpretação da natureza), Diderot formula uma crítica a algumas ideias do Sistema da natureza, no sentido de mostrar que, quando suficientemente desenvolvidas, elas conduziriam ao ateísmo. A resposta de Maupertuis a esse repto, que aqui chamo do "desafio de Diderot", aparece no final do Sistema da natureza, examinada juntamente com a conjectura psicofísica de sua teoria da geração orgânica, mostra-se como um importante exemplo da articulação de questões científicas, teológicas e epistemológicas que caracterizaram a filosofia do materialismo iluminista francês.

O problema principal que o autor põe em perspectiva é o da relação entre as percepções da parte e a do todo, problema clássico de redução ontológica que aparece igualmente em relação à vida e à unidade morfológica e funcional do todo orgânico. A posição de Maupertuis é a de que a agregação das percepções elementares produz uma percepção única mais forte e mais perfeita. A percepção do todo suplanta a das 
As mônadas físicas como unidAdes gerativas no Sistema da natureza...

partes sem destruí-las, o que caracteriza um típico caso de emergência de propriedades. A partir desse resultado, Diderot cria um dilema aplicando a mesma ideia de emergência psicofísica ao cosmo, o que conduziu a uma identificação entre Deus e a totalidade da natureza. É tal identificação que, segundo a acusação de Diderot, conduziria ao ateísmo. Maupertuis nega essa consequência, impondo uma restrição metodológica às aplicações filosóficas que sua teoria permitiria. A afirmação da emergência da percepção do todo a partir das percepções das partes de um organismo individual está justificada na construção de uma teoria física da geração orgânica. Mas a emergência da percepção ou do psiquismo da totalidade da natureza a partir da coleção das percepções dos indivíduos é um passo metafísico que pode ou não ser realizado, sem prejuízo do valor cognitivo da teoria. Na mesma direção, a discussão entre os dois autores também é valiosa para compreender o ressurgimento de imagens organicistas da natureza e da ciência na segunda metade do século Xviı francês como resposta ao suposto afastamento da concretude dos fenômenos naturais ao qual conduziu a física-matemática iluminista (cf. Abrantes, 1998; Ehrard, 1994). Podemos perceber na discussão a grande diferença existente entre as concepções neo-platônicas, que ajustam consistentemente a unidade de uma alma do mundo ao caráter finito, fechado e orgânico do cosmo, e a tradição e as concepções organicistas modernas que tentam conferir unidade orgânica a um universo aberto e infinito.@

\author{
Maurício de Garvalho Ramos \\ Professor Doutor do Departamento de Filosofia, \\ Faculdade de Filosofia, Letras e Ciências Humanas, \\ Universidade de São Paulo, Brasil. \\ maucramos@yahoo.com.br
}

\title{
REFERÊNGIAS BIBLIOGRÁFIGAS
}

Aвrantes, P. Imagens de natureza, imagens de ciência. Campinas: Papirus, 1998.

Beaume, J. - C. et al. (Org.). Buffon 88: actes du colloque international. Paris: J. Vrin/Institut Interdisciplinaire d'Etudes Epistémologiques, 1992.

Bonnet, C. Considerations sur les corps organisés. Amsterdan: Marc-Michel Rey, 1762. t. 1.

Buffon, G.-L. L. Histoire naturelle, générale et particuliére, avec la description du cabinet du roy. Paris:

Imprimerie Royale, 174.9. t. 2.

Duchesneau, F. La physiologie des lumières. Empirisme, modèles et theories. Boston: The Hague, 1982.

Ehrard, J. L'idée de nature en France dans la primière moitié du XVIII siècle. Paris: Albin Michel, 1994.

Freitas, R. S. de. Sociologia do conhecimento: pragmatismo e pensamento evolutivo. Bauru: Edusc, 2003.

Gerhardt, G. J. (Ed.). Die philosophischen schriften von Gottfried Wilhelm Leibniz. Berlin: Georg Olms, 1960. 
Homberg, G. Mémoire touchant les vegetations artificielles. Mémoires de l'Académie Royale des Sciences, p. $426-38,1710$.

Iвraнiм, A. Matière inerte et matière vivante: la théorie de la perception chez Maupertuis. Dix-Huitième Siècle, 24, p. 95-103, 1992.

Leibniz, G. W. Leibniz an Th. Burnett. Hanover 17/27 juillet 1696. In: Gerhardt, G. J. (Ed.). Die philosophischen schriften von Gottfried Wilhelm Leibniz. Berlin: Georg Olms, 1960. p. 179-85. . Systéme nouveau de la nature et de la communication des substances et autres textes: 1690-1703. Paris: Flammarion, 1994.

. Système nouveau de la nature et de la communication des substances aussi bien que de l'union qu'il y a entre l'âme et le corps. In: Systéme nouveau de la nature et de la communication des substances et autres textes: 1690-1703. Paris, Flammarion, 1994. p. 61-90.

. Principes de la nature et de la grâce, Monadologie et autres textes: 1703-1716. Paris: Flammarion, 1996. . Principes de la philosophie [monadologie]. In: Principes de la nature et de la grâce, Monadologie et autres textes: 1703-1716. Paris: Flammarion, 1996. p. 24,1-68.

. A "Protogaea" de G. W. Leibniz (1749). Tradução, introdução e notas N. Papavero, D. M. Teixeira \& M. de C. Ramos. São Paulo: Fapesp/Plêiade, 1997 .

Maupertuis, P.-L. M. Essai de cosmologie. [s.l.]: [s.n.], $175^{1}$. . Oeuvres. Hildesheim: George Olms, 1965 [1768]. v. 2. . Oeuvres. Hildesheim: George Olms, 1974 [1768]. v. 1. . Carta xIv. Sobre a geração dos animais. Tradução M. de C. Ramos. Scientiae Studia, 2, 1, p. 99-128, 2004 . .Vênus física. Tradução e notas M. de C. Ramos. Scientiae Studia, 3, 1, p. 103-4,8, 2005.

Ramos, M. G. Geração orgânica, acidente e herança na Carta xiv de Maupertuis. Scientiae Studia, 2, 1, p. 99-128, 2004.

. A Vênus física de Maupertuis: antigas idéias sobre a geração reformadas pelo mecanicismo newtoniano. Scientiae Studia, 3, 1, p. 79-101, 2005.

. A geração dos corpos organizados em Maupertuis. São Paulo: Associação Filosófica Scientiae Studia/ Editora 34/Fapesp, 2009.

Roger, J. Buffon et l'introduction de l'histoire dans l'histoire naturelle. In: Beaume, J.-C. et al. (Org.). Buffon 88: actes du colloque international. Paris: J. Vrin/Institut Interdisciplinaire d'Etudes Epistémologiques, 1992. p. 193-205.

Rutherford, D. Leibniz and the rational order of nature. Cambridge: Cambridge University Press, 1998.

Terrall, M. The man who flattened the Earth: Maupertuis and the sciences in the Enlightenment. Chicago: University of Chicago Press, 2002.

Westefall, R. S. The construction of modern science: mechanisms and mechanics. Cambridge: Cambridge University Press, 1980.

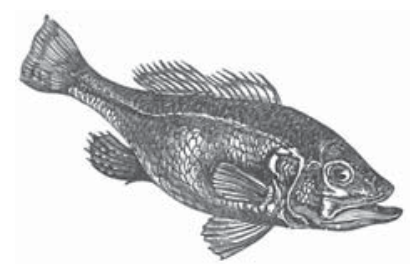

